\title{
Correction to: Three randomized controlled trials evaluating the impact of "spin" in health news stories reporting studies of pharmacologic treatments on patients'/ caregivers' interpretation of treatment benefit
}

Isabelle Boutron ${ }^{1,2,3^{*}}$, Romana Haneef ${ }^{1,2,3}$, Amélie Yavchitz ${ }^{1,3}$, Gabriel Baron ${ }^{3}$, John Novack ${ }^{4}$, Ivan Oransky ${ }^{5}$, Gary Schwitzer ${ }^{6}$ and Philippe Ravaud ${ }^{1,2,3,7}$

Correction to: BMC Med (2019) 17:105

https://doi.org/10.1186/s12916-019-1330-9

Figure 3 in the original article [1] is incorrect; labels for secondary outcomes have been shifted and do not correspond to the numbers reported in the table (Additional File 8).

The corrected version can be seen ahead.

This figure should be used over the Fig. 3 seen in the original article.

This error does not affect the results, interpretation, or conclusion.
Received: 11 July 2019 Accepted: 11 July 2019

Published online: 27 July 2019

\section{Reference}

1. Boutron I, Haneef R, Yavchitz A, Baron G, Novack J, Oransky I, et al. Three randomized controlled trials evaluating the impact of "spin" in health news stories reporting studies of pharmacologic treatments on patients'/ caregivers' interpretation of treatment benefit. BMC Med. 2019;17:105 https://doi.org/10.1186/s12916-019-1330-9.

\section{Author details}

'INSERM, UMR 1153, Epidemiology and Biostatistics Research Center (CRESS), Methods Team, Paris, France. ${ }^{2}$ Faculté de Médecine, Paris Descartes

University, Paris, France. ${ }^{3}$ Centre d'Épidémiologie Clinique, AP-HP (Assistance Publique des Hôpitaux de Paris), Hôpital Hôtel Dieu, 1, Place du parvis Notre Dame, 75004 Paris Cedex 4, France. ${ }^{4}$ Inspire, Arlington, VA, USA. ${ }^{5}$ New York University's Arthur Carter Journalism Institute, New York, USA.

${ }^{6}$ HealthNewsReview.org, University of Minnesota, School of Public Health, Minneapolis, MN, USA. ${ }^{7}$ Department of Epidemiology, Columbia University Mailman School of Public Health, New York, NY, USA.

\footnotetext{
* Correspondence: isabelle.boutron@aphp.fr

${ }^{1}$ INSERM, UMR 1153, Epidemiology and Biostatistics Research Center (CRESS), Methods Team, Paris, France

${ }^{2}$ Faculté de Médecine, Paris Descartes University, Paris, France

Full list of author information is available at the end of the article
}

(c) The Author(s). 2019 Open Access This article is distributed under the terms of the Creative Commons Attribution 4.0 International License (http://creativecommons.org/licenses/by/4.0/), which permits unrestricted use, distribution, and reproduction in any medium, provided you give appropriate credit to the original author(s) and the source, provide a link to the Creative Commons license, and indicate if changes were made. The Creative Commons Public Domain Dedication waiver (http://creativecommons.org/publicdomain/zero/1.0/) applies to the data made available in this article, unless otherwise stated. 


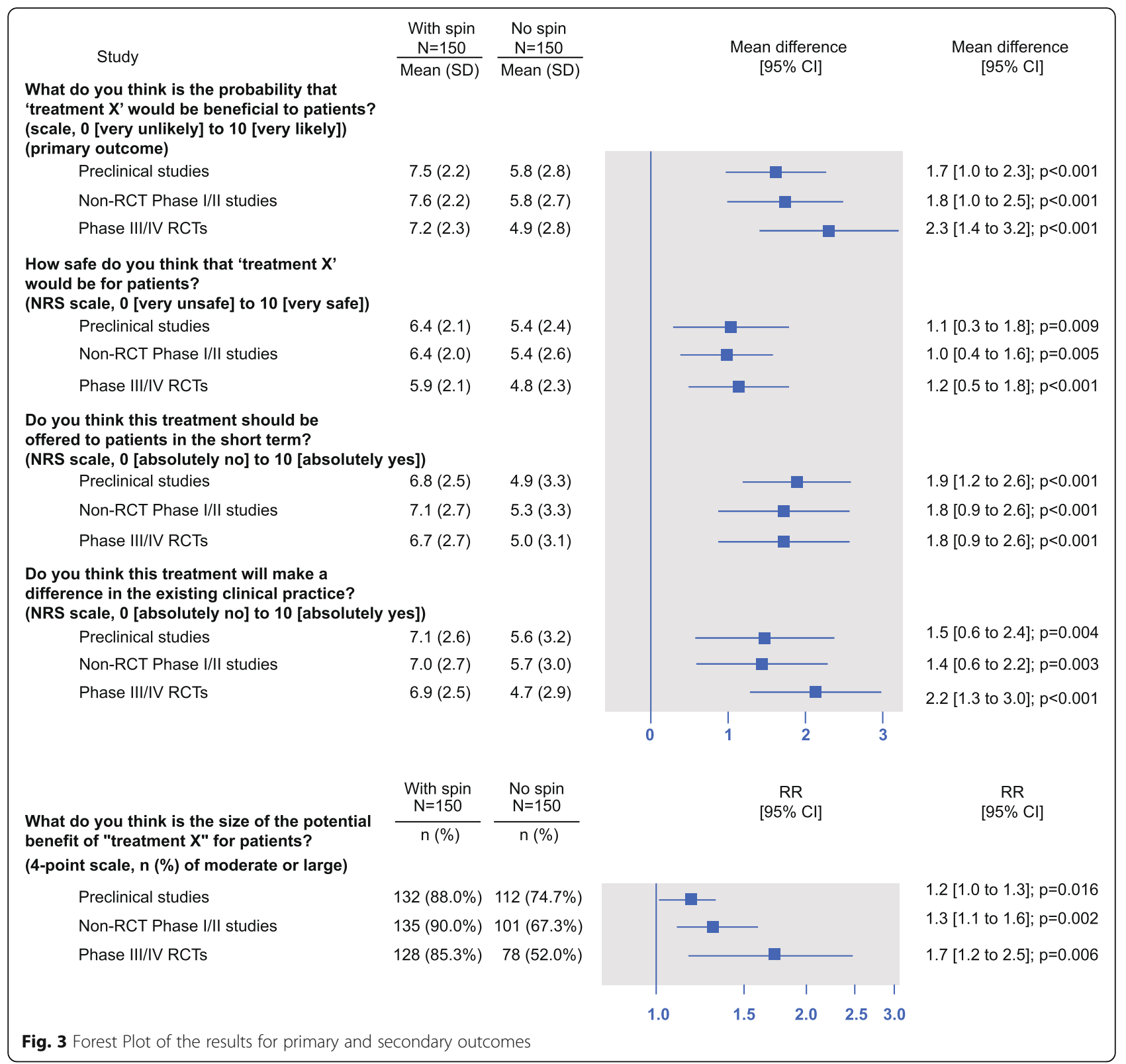

